\title{
VARIABILITY OF THE HEART RHYTHM AS AN ADDITIONAL MARKER FOR DETERMINING VEGETATIVE FUNCTIONS IN PATIENTS WITH CHRONIC CEREBRAL ISCHEMIA
}

\author{
Nataliia Inhula \\ Shupyk National Medical Academy of Postgraduate Education \\ 9 Dorohozhytska str., Kyiv, Ukraine, 04112 \\ inter-dep@nmapo.edu.ua
}

\begin{abstract}
Aim. Practical cardiology is in constant search for non-invasive vascular risk markers. Heart rhythm reflects the body's response to various stimuli of the external and internal environment. Heart rate variability (HRV) has a prognostic and diagnostic value and allows timely identification of conditions that threaten life. The results of an instrumental examination of heart rhythm fluctuations in patients suffering from chronic cerebral ischemia against the background of angina pectoris of different functional classes allows to evaluate the prognosis of the disease and select the appropriate treatment.

Materials and methods. An assessment of the state of the mechanisms of regulation of physiological functions in patients suffering from chronic cerebral ischemia against the background of angina pectoris of different functional classes was obtained according to spectral and temporal analysis of heart rate variability using electrocardiographic monitoring. The spectral characteristics of the heart rate variability were studied: HF (high frequency), LF (low frequency), VLF (very low frequency).

Results. Heart rhythm regulation in patients with chronic cerebral ischemia occurred under the influence of neurohumoral mechanisms. The imbalance of functional systems was caused by changes in the autonomic nervous system, which disrupted the normal functioning of the sympathetic and parasympathetic parts. We marked decrease in the activity of the parasympathetic autonomic nervous system, which changed the indices of spectral analysis, while the high-frequency component of the spectrum was characterized by a decrease, while the low-frequency component was characterized by an increase. The progression of stable angina of tension (SAT) in patients with chronic cerebral ischemia (CCI) occurred with disruption of the autonomic nervous system (ANS) and was associated with a shift in the physiological response towards sympathetic activity. This was particularly pronounced in patients in group 2 with CCI on the background of SAT III FC, as the regulatory mechanisms were in a critical state of tension against the background of long-term chronic ischemia, they showed a high level of humoral modulation of regulatory mechanisms, which was manifested by excessive VLF and high-frequency oscillations.

Conclusions. A connection was established between the autonomic nervous system and chronic cerebral ischemia, which was expressed in the imbalance of the ANS, associated with reliable signs of the dominant sympathetic system, which was associated with the progression of stable angina of tension.
\end{abstract}

Keywords: chronic cerebral ischemia, heart rate variability, autonomic nervous system.

\section{Introduction}

Cardiovascular diseases (CVD) are the leading cause of morbidity and mortality worldwide [1].

Scientific evidence indicates a decline in mortality from CVD in recent years in high-income countries due to preventive measures, however, an average of 17 million deaths are recorded annually in developing countries [2].

Identification of risk factors for cardiovascular pathology is an important issue in cardiology, and the search for non-invasive markers of vascular risk remains one of the most important goals for the scientific community [3].

Scientific interest in the study of HRV as a marker for the risk of sudden cardiac death has grown significantly in recent years [4].

HRV is a change in heart rate (duration of RR intervals) over time.

The study of the neurohumoral mechanisms of heart rhythm regulation in patients with chronic brain ischemia is currently one of the most promising areas in medicine [5]. Registration 
and analysis of HRV allow us to explore the fundamental relationships in the functioning of the cardiovascular system [6].

Determining the degree of tension of regulatory systems is important for assessing the reserve capacity of the organism [7].

HRV allows for a comprehensive study of the functional state of the body with an objective assessment of important life support systems, including cardiac activity, external respiration, the vascular system, the vegetative system, and the mechanisms of humoral regulation. Heart rate variability determines the prognostic value of cardiovascular risk [8].

In the regulation of body functions a large role belongs to the ANS [9].

Numerous experimental studies of domestic and foreign scientists obtained reliable facts about the existence of a link between the tendency to cardiac pathology and imbalance in the ANS [10].

The mechanisms of vegetative regulation provide adaptation to changing conditions at optimal tension of regulatory systems. The work of regulatory systems in an elevated mode leads to an imbalance of vegetative functions and reduces the adaptation and reserve capabilities of the body. It is very important to control how much the vegetative imbalance is disturbed and stable.

ANS maintains homeostasis and ensures the normal functioning of the mental and physical status [11].

According to scientists, the disruption of the vegetative system manifests itself before the morphological imbalance is manifested, while the adaptive function significantly deviates from the norm [12].

The specificity of the regulation of cardiac activity on the part of the central nervous system (CNS) provides the possibility of obtaining prognostic information, both on the activity of the heart, and on changes in the state of the whole organism, since the nervous and humoral regulation of the blood circulation changes before energy, metabolic and hemodynamic violations [13].

Spectral analysis of HRV with the release of the power of the main periods of oscillations (high-frequency, low-frequency, very low-frequency) allows to study the activity of the components of the autonomic nervous system (parasympathetic and sympathetic links) and the effect of brain structures on ANS activity [14].

Although heart rate studies currently occupy an important part in science, in most cases HRV serves as a marker of imbalance in the ANS, than the severity of the disease [15].

The imbalance of the neurohumoral system is manifested by increased activity of the sympathoadrenal and angiotensin-adrenal components [16].

The question of clarifying the prognostic relationship between the autonomous system and the formation of pathological risks, in particular in patients with CCI against the background of SAT [17], remains a questionable question.

\section{Aim of the research}

To determine changes in heart rate variability in patients with chronic cerebral ischemia against the background of angina pectoris of different functional classes.

\section{Materials and methods}

The study was conducted in the period from 2014 to 2018. The study of HRV was conducted with the participation of patients diagnosed with CCI. Patients were examined at the bases of the Department of Neurology and Reflex Therapy in the structural units of the Shupyk National Medical Academy of Postgraduate Education: KU KOS Kiev Regional Clinical Hospital (neurological department), Amosov National Institute of cardiovascular surgery (Department of surgery for coronary heart disease, Department of surgical methods of diagnosis and treatment of diseases of the heart and blood vessels).

The groups were comparable in age and sex. The age of the examined varied from 45 to 74 years (mean age 58.85 \pm 7.01 ). All examined were divided into groups: 1 group -45 patients ( 29 men and 16 women) with CCI and SAT II FC, group 2-45 patients (32 men and 13 women) with CCI 
against the background of SAT III FC. The comparison group consisted of 30 people (10 men and 20 women) with CCI (Table 1).

Table 1

Clinical characteristics of the examined groups

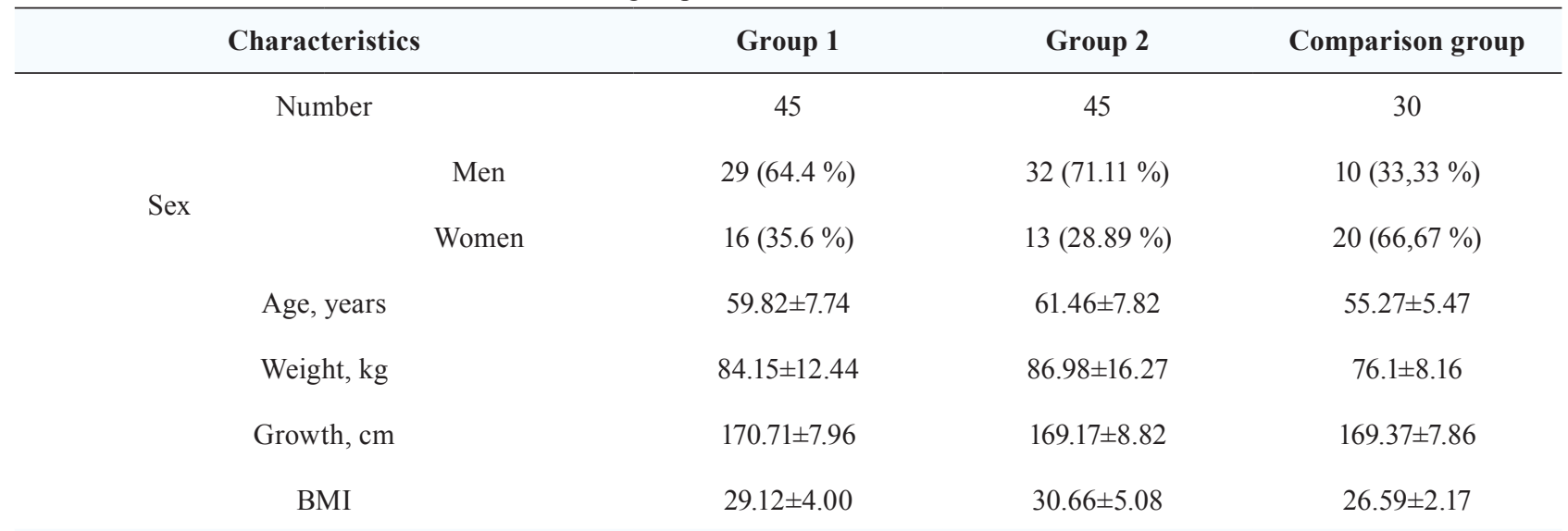

\section{Results of the research}

The results of the study of the spectral characteristics of HRV showed that in all three groups an increased VLF was observed, which is responsible for the level of humoral modulation of regulatory mechanisms. A significantly elevated level of this indicator, which was in the range of 4000-6000 ms, was found in groups 1 and in the comparison group, which was interpreted in patients as a state of overreaction - hyperaemia, which requires restoring the energy expenditure balance; while in patients of group 1 VLF was closer to the maximum of the limits, and in the comparison group - to the minimum.

In group 2, the VLF index was $7298.44 \pm 96.86 \mathrm{~ms}^{2}\left(\sim 6000 \mathrm{~ms}^{2}\right)$, which we considered as a significant imbalance in the expenditure of vitality and the presence of autonomic dysfunction (Table 2).

Table 2

Parameters of temporal and spectral characteristics of HRV

\begin{tabular}{cccc}
\hline Parameters & Group 1 & Group 2 & Comparison group \\
\hline VLF, $\mathrm{ms}^{2}$ & $5678.33 \pm 88.96$ & $7298.44 \pm 96.86$ & $4318.79 \pm 65.72$ \\
LF (1170416 $\left.\pm \mathrm{ms}^{2}\right)$ & $1408.2 \pm 40.93$ & $1870.94 \pm 19.23^{*}$ & $1286.33 \pm 35.87$ \\
HF (975203 $\left.\pm \mathrm{ms}^{2}\right)$ & $386.86 \pm 17.46^{*}$ & $541.29 \pm 17.9^{*}$ & $489.52 \pm 22.13^{*}$ \\
LF/HF (1.5-2.0) & $3.64 \pm 1.24^{*}$ & $3.46 \pm 1.11^{*}$ & $2.63 \pm 1.73^{*}$ \\
LFn, 54 \pm 4 n. u. & $68.31 \pm 2.97$ & $71.22 \pm 2.71$ & $69.1 \pm 8.31$ \\
HFn, 29 $\pm 3 \mathrm{n} . \mathrm{u}$. & $29.22 \pm 3.13$ & $29.58 \pm 3.63$ & $28.93 \pm 5.34$ \\
\hline SDNN (141 $\pm 39 \mathrm{~ms})$ & Temporal characteristics & $161.42 \pm 58.52$ & $13.8 \pm 3.71$ \\
pNN50, \% & $144.95 \pm 6.31$ & $9.31 \pm 3.4$ & $75.77 \pm 8.7$
\end{tabular}

Note: *- significance of differences to the norm $(p<0.05)$ 
In patients of group 2, a statistically confirmed dominance of the activity of oscillations of a low frequency of LF was found (37.46 \% above the norm), which indicated the advantage of the influence of the work of the sympathetic system in SAT III FC. In groups 1 and in the comparison group, this indicator was also increased, respectively by 16.9 and $9.04 \%$, but there were no statistically significant differences with the norm. High frequency fluctuations of HF were low in all patients, while in group 1 this indicator was lower by $60.32 \%$ of the norm, in group 2 - by $44.48 \%$, and in comparison group - by $49.79 \%$. All indicators were statistically significant.

Characteristic level of sympathetic-vagal balance - the index of vagosympathetic interaction $\mathrm{LF} / \mathrm{HF}$, revealed a statistically significant predominance of sympathetic reaction over the parasympathetic, which was characterized by an increase in the index of vegetative balance from the maximum norm level in group 1 by $54.95 \%$, in group 2 - by $64.5 \%$, and in the comparison group - by $31.5 \%$.

The centralization index IC $((\mathrm{HF}+\mathrm{LF}) / \mathrm{VLF})$ was distributed in the groups as follows: group $1-0.25$, group $2-0.33$, comparison group -0.41 . In all groups, the IC index was significantly reduced, which indicated that the regulation of physiological functions took place with the advantage of central influences, reflecting the voltage of the functioning of the system. LFn was raised in groups as follows: by $26.5 \%$ in group 1 , by $31.89 \%$ in group 2 , and by $27.96 \%$ in the comparison group. HFn was within the normal range of all groups.

The spectral indices of HRV in patients showed an advantage of sympathetic effects on the heart muscle.

Analysis of the obtained temporal characteristics of HRV showed that RMSSD was within the normal range in groups 1 and 2 and increased in the group compared to $47.93 \%$.

SDNN had an elevated level in group 2 by $14.5 \%$ of the norm, in the comparison group it was $10.6 \%$ and in group 1 it was increased slightly.

\section{Discussion of the results}

Examination of patients showed that changes in the autonomic nervous system were associated with functional imbalances, leading to impaired sympathetic and parasympathetic regulatory influences. The obtained data is confirmed by the information [18] of the increase in the temporal analysis of HRV associated with increased parasympathetic influences, and the decrease with the activation of the sympathetic tone. Since the heart rate is largely controlled by the ANS, the change in the cardiovascular system and heart rate is the most striking indicator of deviations arising in regulatory systems. They precede hemodynamic, metabolic, energy disorders and may reflect early prognostic signs of imbalance in patients, in accordance with [19]. Similar information was obtained in our studies. The activation of the sympatho-adrenal system and the decrease in the activity of the parasympathetic division of the autonomic nervous system deserve special attention, associated with the restructuring of the cardiovascular system (CVS), which is reflected in the deterioration of the characteristics of the spectral analysis with a decrease in high hourly total and increased low-frequency components of the spectrum.

The results we obtained of modern methods for estimating diurnal HRV, temporal and spectral, showed that the progression of stable SAT in patients with CCI was associated with ANS imbalance, which was due to the predominant shift of the physiological response towards sympathetic activity in patients in group 1 with CCI against SAT II FC, which confirms studies [20] that ischemic stroke is associated with changes in autonomic cardiac dynamics, cardiac arrhythmias, and acute myocardial damage by changing the balance of sympathetic and parasympathetic tone.

In group 2, in the examined patients with SAT III FC, the regulatory mechanisms were in a critical state of tension, they showed a high level of humoral modulation of the regulatory mechanisms, which was manifested by an excessive level of VLF, the dominance of high-frequency oscillations. 


\section{Conclusions}

1. An imbalance of ANS was found in patients with CCI against the background of ANS, which was characterized by a decrease in parasympathetic and increase in sympathetic effects on the cardiovascular system.

2. The degree of overvoltage of the sympathetic division of the ANS in determining autonomic reactivity was most pronounced in patients of group 2 (CCI with SAT III FC), which mobilized protective mechanisms and increased the activity of sympathetic regulation while preserving the body's adaptation reserves.

3. The state of depletion of regulatory systems caused the activity of the sympathetic division of the SNS with a decrease in protective parasympathetic influences, which reflected the influence of the suprasegmental level of regulation, leading to energy-deficient states.

\section{References}

[1] Benjamin, E. J., Blaha, M. J., Chiuve, S. E. et. al. (2017). American Heart Association Statistics Committee and Stroke Statistics Subcommittee. Heart disease and stroke statistics - 2017 update: a report from the American Heart Association. Circulation, 36, 196.

[2] Niemeijer, M. N., van den Berg, M. E., Leening, M. J. G., Hofman, A., Franco, O. H., Deckers, J. W. et. al. (2015). Declining incidence of sudden cardiac death from 1990-2010 in a general middle-aged and elderly population: The Rotterdam Study. Heart Rhythm, 12 (1), 123-129. doi: http://doi.org/ 10.1016/j.hrthm.2014.09.054

[3] Kornackii, V. M. (2013). Problema boleznei sistemy krovoobrashcheniy aiputieeminimizaciiv Ukraine. Kardiologiya, 5, 10-13.

[4] Jouven, X., Empana, J.-P., Schwartz, P. J., Desnos, M., Courbon, D., Ducimetière, P. (2005). Heart-Rate Profile during Exercise as a Predictor of Sudden Death. New England Journal of Medicine, 352 (19), 1951-1958. doi: http://doi.org/10.1056/nejmoa043012

[5] Sörös, P., Hachinski, V. (2012). Cardiovascular and neurological causes of sudden death after ischaemic stroke. The Lancet Neurology, 11 (2), 179-188. doi: http://doi.org/10.1016/s14744422(11)70291-5

[6] Boos, C. J., Vincent, E., Mellor, A., O’hara, J., Newman, C., Cruttenden, R. et. al. (2017). The Effect of Sex on Heart Rate Variability at High Altitude. Medicine \& Science in Sports \& Exercise, 49 (12), 2562-2569. doi: http://doi.org/10.1249/mss.0000000000001384

[7] Baevskii, R. M., Ivanov, G. G.; Grachev, S. V., Syrkin, A. L. (Eds.) (2007). Variabel'nost' serdechnogo ritma: teoreticheskie aspekty i vozmozhnosti klinicheskogo primeneniya. Novye metody ehlektrokardiografii. Moscow: Tekhnosfera, 474-496.

[8] Mashin, V. A. (2011). Factor analysis of the heart rate spectrum. Biophysics, 56 (2), 286-297. doi: http://doi.org/10.1134/s0006350911020217

[9] Vein, A. M. (2000). Vegetativnye rasstroistva: Klinika. Diagnostika. Lechenie. Moscow: MIA, 749.

[10] Avetisyan, E., Petrosyan, A., Avanesyan, L., Shogheryan, S., Saakyan, N. (2018). Restoration of sympatho-parasympathetic balance in heart rate variability in the development of psychoemotional stress against the background of taurine in experiment. Georgian Med News, 1 (274), 168-173.

[11] Hung, Y. C. (2011). Circadian Patterns of Heart Rate Turbulence, Heart Rate Variability and Their Relationship. Cardiology Research, 2 (3), 112-118.

[12] Pokrovskii, V. M.; Pokrovskii, V. M. (Ed.) (2010). Serdechno-dyhatel'nyi sinhronizm v ocenke regulyatorno-adaptivnyh vozmozhnostei organizma. Krasnodar, Izd-vo «Kuban'-kniga», 244.

[13] Zaripov, V. N., Barinova, M. O., Vtulova, E. V. et. al. (2005). Izmenenie vegetativnogo statusa studentov na ehmocional'no znachimyh ehtapahuchebnogoprocessa. Mat. I s"ezdafiziologov SNG. Moscow: Medicina, 2, 275.

[14] Shlyk, N. I.; Shlyk, N. I., Baevskii, R. M. (Eds.) (2016). Ritm serdca i tip vegetativnoi regulyacii $\mathrm{v}$ ocenke urovnya zdorov'ya naseleniya i funkcional'noi podgotovlennosti sportsmenov. Izhevsk: Izdatel'skii centr «Udmurtskii universitet», 608.

[15] Vaihanskaya, T. G., Sidorenko, I. V., Frolov, A. V. et. al. (2013). Variabel'nost' serdechnogo ritma v patofiziologii reinnervacii transplantirovannogo serdca. Kardiologiya v Belarusi, 4 (29), 38-50. 
[16] Kulaichev, A. P. (2007). Metody i sredstva kompleksnogo analiza dannyh. Moscow: FORUM-INFRA, 640.

[17] ESH-ESC Guidelines Committee. 2007 guidelines for the management of arterial hypertension (2007). Journal of Hypertension, 25, 1105-1187.

[18] Bokeriya, L. A., Bokeriya, O. L., Volkovskaya, I. V. (2009). Variabel'nost' serdechnogoritma: metodyizmereniya, interpretaciya, klinicheskoeispol'zovanie. Annaly aritmologii, 4, 21-32.

[19] Jouven, X., Empana, J.-P., Schwartz, P. J., Desnos, M., Courbon, D., Ducimetière, P. (2005). Heart-Rate Profile during Exercise as a Predictor of Sudden Death. New England Journal of Medicine, 352 (19), 1951-1958. doi: http://doi.org/10.1056/nejmoa043012

[20] Finsterer, J., Wahbi, K. (2014). CNS-disease affecting the heart: Brain-heart disorders. Journal of the Neurological Sciences, 345 (1-2), 8-14. doi: http://doi.org/10.1016/j.jns.2014.07.003 